\title{
Scope of practice in Primary Care: physicians and nurses in five health regions in Brazil
}

Sabado Nicolau Girardi 1

Ana Cristina de Sousa van Stralen 2

Thais Viana Lauar 3

Joana Natalia Cella 4

Jackson Freire Araújo 5

Célia Regina Pierantoni 6

Cristiana Leite Carvalho 7

1-5,7 Estação de Pesquisa em Sinais de Mercado EPSM/FM/NESCON. Universidade Federal de Minas Gerais. Av Prof. Alfredo Balena, 190. Belo Horizonte, MG, Brasil. CEP: 30.130-100. E-mail: anastralen@gmail.com

6 Departamento de Política, Planejamento e Administração em Saúde. Instituto de Medicina Social. Universidade do Estado do Rio de Janeiro. Rio de Janeiro, RJ, Brasil.

\section{Abstract}

Objectives: The review on scopes of practice tends to gain importance in Human Resource in Health agenda in Brazil. The aim of this study was to investigate the scope of practice of physicians and nurses who work in the Atenção Primária em Saúde (APS) (Primary Healthcare) and their main barriers.

Methods: this is an exploratory qualitative study conducted in 2015 and 2016, through interviews with 26 physicians and 26 nurses who work in the APS in 12 cities distributed in five Brazilian health regions.

Results: physicians and nurses in the health region of the North and Northeast performed a great number of procedures, and those physicians who work in units located in rural areas. Both professional categories indicated that they knew how to carry out several procedures that were not performed in practice. The main barriers for not performing those procedures include, lack of access to exams, materials and inadequate infrastructure, protocols and city guides restrictions, legal restrictions and lack of training.

Conclusions: the results suggests the need to ease the health professionals'attributions, facilitate the integration between the professionals' practices and optimizing their work, especially in remote and unassisted regions, in order to be in favor of expanding the access and problem solving in APS.

Key words Primary healthcare, Human Resource in Health, Professional practice, Health workforce 


\section{Introduction}

The term "scope of practice" refers to a comprehensive set of attributions, functions and activities of a certain occupation. The composition and exact integration of these functions and activities varies according to the professional, the needs and demands for a given service and the organizations, institutions and locations where this professional is inserted. ${ }^{1}$ From this perspective, the scope of practice is determined from the processes of interaction between the agents and the institutions, which include from the professional regulation, in other words, those activities authorized by law, the activities that the professional performs in practice and has competence to perform, considering both the skills gained through study and practice as on the individual's qualities and attitudes. ${ }^{2-4}$

In the health area, the form how professional practice are defined, limited or extended, directly impacts the quality and cost of services. 5 On the other hand, the factors that determine these practices are different from what has been shown in several studies on the theme, in which the scope of health professionals has been associated, among others, to factors such as nationality, sex, age, education, experience and location of practice, such as remote and unassisted areas or with low availability of health professionals.2,5-7

The Atenção Primária em Saúde (APS) (Primary Health Care) in several countries has gone through significant changes with respect to the number and types of health professionals and their roles in the health services. 8,9 Countries such as Australia, Canada, the United States and England are reviewing of the scope of health professions, seeking each time more in optimizing their workforce, reducing costs, providing greater equity and quality in service provision, mainly in regions that present shortage of these professionals. Strategies were adopted by these countries including the adoption of new health professions, as for example physician assistants, nurse practitioners; the function transference between professional with hight category level or technical category level - task shifting or skill mix, as nurses performing certain medical procedures; the expansion of primary care health professionals scope of practice, as physicinas performing tasks usually attributed to specialists. ${ }^{9-13}$

In Brazil, the APS is the preferential entrance to the Sistema Único de Saúde (SUS) (Public Health System) and the scope of practice for health professionals who work in this context influence directly the referrals rates and lines at secondary and tertiary care and, consequently, costs and access to health. ${ }^{5}$ Due to this, the processes of regulation and workforce training, along with the reform models of service provision, mainly in primary care, has, over the past few years, been at the center of the policy agenda of Human Resources for Health in Brazil. This present article aims to investigate the scope of practice of physicians and nurses who worked at APS and their main barriers in five Brazilian health regions.

\section{Methods}

This is an exploratory and descriptive study on the scope of practice of professionals who work at APS, based on the results of the research 'Regulação das Profissões de Saúde' (Regulation of Health Professions), conducted by the Observatórios de Recursos Humanos em Saúde, Estação de Pesquisa de Sinais de Mercado da Universidade Federal de Minas Gerais (EPSM/UFMG) (Observatories of Human Resources for Health, Research Station of Market Signs at the Universidade Federal de Minas Gerais) and Estação de Trabalho do Instituto de Medicina Social da Universidade Estadual do Rio de Janeiro (IMS/UERJ) (Work Station of the Institute of Social Medicine at the Universidade Estadual do Rio de Janeiro). ${ }^{14}$ The research had as one of its central objectives to identify the attributions, competence and the scope of practice of different health professions (nurses, dentistsurgeons, pharmacists, physiotherapist, physicians, nutritionists and psychologists) in the scope of services that form the healthcare networks, and the interfaces among the professions.

In this present article we will present relative data on the results of interviews made with physicians and nurses which occurred in August 2015 until June 2016. The scenarios delimited for this study were the Health Regions, object of the research 'Politica, Planejamento e Gestão das Regiões e Redes de Atenção à Saúde no Brasil' (Policy, Planning and Management in Regions and Healthcare Networks in Brazil), which defined the regions and cities to be visited. 15

The research contemplated health regions with distinct social profiles and services, according to the criteria of territorial administrative, socioeconomic development and complexity of the healthcare system, namely: North and South Barretos (São Paulo); the Rede Interestadual de Saúde do Vale Médio São Francisco (Interstate Health Network of the Middle São Francisco Valley), known as PEBA, specifically the macro-regions Petrolina 
(Pernambuco) and Juazeiro (Bahia); Entorno, Manaus (Amazonas); Baixada Cuiabana (Mato Grosso); and Carbonífera/Costa Doce (Rio Grande do Sul).

The selection for the interviewees occurred according to the location of the Unidade Básica de Saúde (UBS) (Basic Health Unit) and the professional category. For the selection, an open consultation was conducted prior to the Cadastro Nacional de Estabelecimentos de Saúde (CNES/MS) (National Registration of Health Establishments) in June 2015, taking into consideration the location of the UBS, if it was in a rural area, urban (downtown or neighborhood) or vulnerable area (such as the peripheral areas or socioeconomically vulnerable in urban centers). Prioritizing those who provided dental care service and had support from the professionals at the Núcleo de Atenção em Saúde da Familia (NASF) (Family Healthcare Nucleus), for which the professional categories of interest could be interviewed at each location.

The research instruments were constructed from consulting protocols of Atenção Básica do Ministério da Saúde (MS) (Basic care of the Ministry of Health), interviews with key informants/professionals of assistance and the international literature review.5,16-18 Semi-open questionnaires were elaborated with pre-defined themes related to the scope of practice of professionals in the APS according to a list of procedures, activities and actions, respectively 49 items for the physicians and 34 items for the nurses.

The interviewees were asked, among other questions, to indicate which activities are "performed" in the UBS, which "do not perform, but know how to perform" and which "do not know how to perform". It was also requested to the professionals to indicate the main reasons for not performing the activities that they know how to perform and those that could be performed to improve access and service quality. The North and South of Barretos were the first and served as a pre-test of the instrument, which has undergone some alterations in other fields. ${ }^{14}$ In total, 26 physicians and 26 nurses were interviewed. All the participants signed an Informed Consent Form (ICF). The project was submitted to be evaluated by the Research Ethics Committee at the IMS/UERJ, under CAAE Registration number 46779115.5.0000.5260 and the Decree statement number 1,248.858 on September 29th, 2015.

After transcribing the interviews, a thematic analysis was conducted. 19 Initially, the pre-analysis was performed from a "flowing reading", activity that allowed to generate initial impressions about the collected material. Afterwards, the exploration of material was performed, in which were clipped, of the interviews, relevant information, seeking to classify those clippings in categories, that included the main reasons presented by the professionals for not performing certain procedures, health services and actions and the opinion about the expansion of the scopes of practice of the professionals at the APS.

Finally the results were grouped, treated and interpreted. The sociodemographic data (age and sex) and the reference relating to the scope of practice (percentage of procedures, activities and health actions that the professionals performed and did not perform but know how to perform) were described according to the distribution of frequencies. Some data on the profile, such as nationality, and the name of the city where the interview took place were not discriminated in order to preserve the anonymity of the interviewee.

\section{Results}

\section{Physicians}

Table 1 presents the physicians' age and sex, the UBS location and the percentage of the procedures by health region visited and what each interviewee stated in the unit, the procedures that he/she does not perform but knows how to perform, and procedures that he/she does not know how to perform.

The interviewees' profiles were quite varied according to sex and age. Seven of the interviewees were Cubans and one was Venezuelan. Most of the interviewees had fellowship of the Programa Mais Médicos (PMM)/Programa de Valorização da Atenção Básica (PROVAB) (n=13) (More Physicians Program/ (Recovery of Primary Care Program), eight were statutory, four had temporary contracts and one was a CLT (Consolidação das Leis do Trabalho) employee (Consolidation of Labor Laws). Most of them had medical specialty $(\mathrm{n}=19)$, predo-minantly in Family Medicine and Community. Nine of the interviewed physicians mentioned to be working in another location, besides the unit visited.

Despite this is not a comparative study, we observed some differences in the scope of these professionals, depending on the characteristics of the working place. The regions in which the physicians in units located in the rural areas were interviewed (North/South Barretos, Entorno, Manaus and Baixada Cuiabana) it was possible to observe that these physicians performed a larger number of procedures in relation to their peers who work in urban units and/or in vulnerable areas within the 
Table 1

Unit Type, age, sex and percentage of procedures that physicians perform and know how to perform in the health region.

\begin{tabular}{|c|c|c|c|c|c|c|}
\hline Health Region & UBS (location type) & Age & Sex & $\begin{array}{c}(\%) \text { of procedures } \\
\text { performed }\end{array}$ & $\begin{array}{l}(\%) \text { of procedures that } \\
\text { are not performed, but } \\
\text { knows how to perform }\end{array}$ & $\begin{array}{l}\text { (\%) of procedures } \\
\text { that do not know } \\
\text { how to perform }\end{array}$ \\
\hline North and South & Urban & 38 & $\mathrm{~F}$ & 25.5 & * & * \\
\hline \multirow[t]{4}{*}{ Barretos (SP) } & Urban & 53 & $\mathrm{~F}$ & 38.3 & * & * \\
\hline & Rural & 49 & $\mathrm{~F}$ & 63.8 & * & * \\
\hline & Urban & 29 & $M$ & 44.7 & * & * \\
\hline & $(\%)$ in the region & & & 43.1 & & \\
\hline \multirow[t]{7}{*}{ PEBA (BA/PE) } & Urban & 32 & $M$ & 67.3 & 24.5 & 8.2 \\
\hline & Urban & 28 & $\mathrm{~F}$ & 65.3 & 24.5 & 10.2 \\
\hline & Urban & 27 & $M$ & $* *$ & ** & ** \\
\hline & Urban & 29 & $M$ & 42.9 & 46.9 & 10.2 \\
\hline & Urban & 49 & $\mathrm{~F}$ & 36.7 & 53.1 & 10.2 \\
\hline & Urban & 46 & $\mathrm{~F}$ & 69.4 & 30.6 & 0 \\
\hline & $(\%)$ in the region & & & 56.3 & 35.9 & 7.8 \\
\hline Entorno de & Vulnerable Areas & 39 & $\mathrm{~F}$ & 32.7 & 42.9 & 24.5 \\
\hline \multirow[t]{6}{*}{ Manaus (AM) } & Vulnerable Areas & 39 & $M$ & 32.7 & 44.9 & 22.4 \\
\hline & Urban & 41 & M & 46.9 & 38.8 & 14.3 \\
\hline & Vulnerable Areas & 44 & $\mathrm{~F}$ & 42.9 & 30.6 & 26.5 \\
\hline & Rural & 60 & $M$ & 67.3 & 26.5 & 6.1 \\
\hline & Urban & 33 & $M$ & 42.9 & 38.8 & 18.4 \\
\hline & $(\%)$ in the region & & & 44.2 & 37.1 & 18.7 \\
\hline Baixada Cuiabana & Rural & 27 & $\mathrm{~F}$ & 53.1 & 36.7 & 10.2 \\
\hline \multirow[t]{4}{*}{ (MT) } & Urban & 28 & $\mathrm{~F}$ & 32.7 & 49.0 & 18.4 \\
\hline & Urban & 32 & $\mathrm{~F}$ & 36.7 & 28.6 & 34.7 \\
\hline & Vulnerable Areas & 28 & $\mathrm{~F}$ & 30.6 & 59.2 & 10.2 \\
\hline & $(\%)$ in the region & & & 38.3 & 43.4 & 18.4 \\
\hline Carbonífera/ & Vulnerable Areas & 26 & $\mathrm{~F}$ & 28.6 & 32.7 & 38.8 \\
\hline \multirow[t]{6}{*}{ Costa Doce (RS) } & Urban & 28 & $\mathrm{~F}$ & 44.9 & 40.8 & 14.3 \\
\hline & Vulnerable Areas & 33 & $M$ & 51.0 & 46.9 & 2.0 \\
\hline & Urban & 46 & $\mathrm{~F}$ & 24.5 & 37.2 & 38.3 \\
\hline & Vulnerable Areas & 48 & $M$ & 57.1 & 30.6 & 12.2 \\
\hline & Urban & 47 & $M$ & 57.1 & 36.7 & 6.1 \\
\hline & $(\%)$ in the region & & & 43.9 & 37.5 & 18.6 \\
\hline
\end{tabular}

* Pre-test questionnaire, did not have the question; **Interviewed did not answer the question.

Source: Elaborated by the authors from the data collected in the field, 2015-2016. 
region. However, when we observe the individual cases, the highest percentage of procedures performed by a physician interviewed in a city far from the PEBA Network (69.4\%), and a physician in a rural area with difficult access (only fluvial) in the region of Entorno, Manaus (67.3\%). (Table 1).

However, the interviews also indicated some cases of physicians within the same region and the same typology unit with the percentages quite in discre-pancy regarding to the procedures in the practice that they perform, such as the case of two interviewees in the same city of PEBA Network, in which one performs $36.7 \%$ of the procedures listed and the other, $69.4 \%$ (Table 1), which may reflect on other factors, such as the organization and the unit management, the patients' demands, besides the individual and subjective questions of the professional himself.

When we analyzed by health region, the interviewed physicians in the PEBA Network reported to have performed a higher percentage of procedures in relation to other health regions $(56.3 \%)$. Those who were interviewed in Baixada Cuiabana presented the lowest percentage of performing procedures (38.3\%). (Table 1).

Table 2 presents the list of procedures, health activities and actions, as well as the frequency and percentage of the physicians who mentioned that they performed theses procedures in the UBS, namely to know how to perform and did not know how to. The most common activities performed by almost all the interviewed physicians, included treatments for recurrent urinary infection, recurrent sinusitis, skin diseases, back pain, asthma, anemia, epigastralgia and superficial mycoses. In general, it was possible to observe that the interviewees from all regions knew how to perform various procedures that were not performed in practice at the health unit where they work.

In the procedures performed by less than a quarter of the interviewees - however, more than half reported to know how to perform the procedures were included: incision and drainage of abscess, infiltration of local anesthetic, surgical sutures, electrocardiogram, immobilization of fractures, removal of cysts, lipomas and nevi, removal of ingrown nail, removal of skin lesions and normal low risk delivery (Table 2).

These activities and several others that could be performed at the APS and, therefore, contribute in reducing the lines in secondary and tertiary care units, that were not performed, according to the interviewees, mainly due to the lack of materials and inadequate infrastructure.
"I refer all the otolaryngology section $[\ldots]$ more strange body because we do not have working instrument". (Physician 6, Entorno, Manaus).

"I refer them to the orthopedist a lot. If there was an efficient X-Ray service here, I could have already done the $\mathrm{X}$-rays, and see them in time and be able to treat the patient without the need to refer the patient to go to another place to do this procedure." (Physician 2, Baixada Cuiabana)

However, some interviewees reported performing certain procedures, even in the absence of adequate infrastructure:

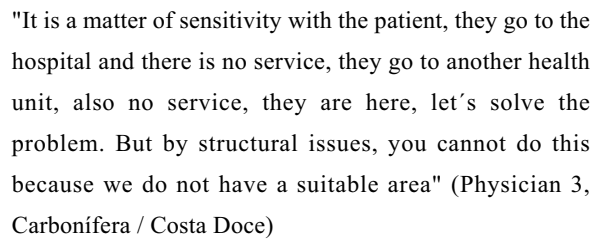

The physicians also reported that there are certain procedures they do not perform because these procedures are performed by other healthcare professionals of the unit, such as venous puncture and the insertion of a nasogastric tube, commonly performed by nurses. In this context, one of the interviewees in of PEBA Network addressed the necessity to formalize with the nurses to share tasks:

\footnotetext{
"There are things that should be shared with other nursing professionals. We do not do it, it is not due to lack of availability of these professionals, it is because we have never sat down to share it. It is a matter of organization" (Physician 3, PEBA)
}

It was reported the fact that certain procedures were not listed in the protocols and in the primary care guidelines in the cities. "Minor surgery could be performed as well. Patients who need intravenous treatment $[. .$.$] but if I follow the protocol and I have$ to refer to secondary care" (Physician 6, Entorno, Manaus)

"Imagine placing an IUD in women in a rural community! But, I did it, I placed more than 20 IUDs. [...] But then came the manager's orientation that this procedure was not to be done here anymore, that all these cases should be forwarded to family planning. From a practical point of view, it is worse, because I referred the patients, there are a few who have access, that they can make an appointment and are able to place the IUD. 
$[\ldots]$

Here we perform prenatal care follow up. High risk we are instructed to refer them. But, many times, the patient will not go. She wants to do it here! And we say: "No, you have to go there and, anything, any doubt, you can come back here." Nowadays, it is a real issue, it is the distance, it is the bus fare... You see that she is not going there".

(Physician 3, Baixada Cuiabana)

The difficulty in performing some procedures and to treat certain patients, according to some interviewees' reports it is due to the lack of permission for clinicians at the APS request high cost examinations. This ends up delaying the patient's treatment, since the consultation for certain specialities may take months to years to do them.

"[...] Here in the city, for you to ask for an echocardiogram, it has to be done by a cardiologist. And I usually say that I have criteria, I know why to ask, I know how to evaluate. I understand that this is the way to be limited $[\ldots]$ because there are a lot of people who asks without criteria. The same thing [happens] with the endoscopy [... I cannot ask directly. As I am very fussy, sometimes I argue and get what I want" (Physician 1, PEBA)

Some physician emphasized that the population has the habit of looking directly for the specialist and this interferes with the performed activities. In some cases the patient himself demands to be referred to secondary care.

"They are spoiled here, the pregnant women go straight to the gynecologist and the infants to the pediatrician (...). The patients go straight to the specialists" (Physician 2, North / South Barretos).

"We Cuban physicians were a little frustrated. Basic care does not work as it should, it is is too much to prescribe a prescription (...) If you have high blood pressure, you should go straight to the cardiologist, but you could start the treatment here. If you start the treatment here and it does not solve the problem, then the patient is referred to a specialist" (Physician 4, North / South Barretos)

The population is used to going to the hospital, even for a simple headache, or for a consultation to measure the pressure of the vision. It is not for them to go, but they go any way. Then it is overcrowded. (...) $80 \%$ of the things done at the hospital, is not supposed to be done there, it is supposed to be done in the health unit. (Physician 3, Carbonífera / Costa Doce)

The lack of training for certain procedures was also mentioned. Among the activities listed, one third or more of the interviewees reported not knowing how to perform procedures, such as: to remove a determined fungus, removal of a contagious mollusk, chemical cryotherapy, removal of callus, drainage of paronychia, treatment for bruises, removal of strange bodies from the cornea or conjunctiva, diagnostic on complaints of reduced visual acuity, screening on visual acuity and acupuncture (Table 2).

Most of the physicians agree that they could expand their practices in the health units and attribute considering advantageous the improvement of the effectiveness, reducing lines, better control of patients attended at the units, as well as to facilitate for the population who lives in far away areas and have difficulty to access.

"You have to remove a strange body, you have to cross the river and go to Manaus. And when the river is low tide, nobody comes to get you and nobody leaves" (Physician, 5, Entorno, Manaus).

However, one of the interviewees proved to be more resistant, especially regarding to the specific attributions of each professional:

"I do not see it this way, no, I do not, I think that the specialist has his/her role and I have mine" (Physician 2, Entorno, Manaus)

Another interviewee stressed the very lack of willingness and good will of doctors in expanding its activities:

"(...) Any clinician has the capacity to do this [removal of lipomas, abscess drainage), but two things come to my mind, one is the lack of equipment and the structure in the health unit, but there is another thing, there are physicians who do not want to do this. You will have to excuse me, but here the general clinician is simply an intermediate between the patient and the specialist. They do not do anything else except refer you to a specialist and prescribe anti-inflammatory, antibiotics and analgesics. The general clinician, in my opinion, has very little resolution here in the city. You make an appointment with the clinician just to get a paper and go to another physician. We could do a lot of things at the health unit if there were service provision and good will." (Physician 3, Carbonífera / Costa Doce)

\section{Nurses}

The 26 nurses interviewed were predominantly 
Distribution of procedures, health services and actions of physicians at the UBS that performed, did not perform, but know how to perform and do not know how to perform.

\begin{tabular}{|c|c|c|c|c|c|c|c|}
\hline \multirow{2}{*}{\multicolumn{2}{|c|}{ Health procedures, services and actions }} & \multicolumn{2}{|c|}{ Performed ( $N=25)$} & \multicolumn{2}{|c|}{$\begin{array}{l}\text { Are not performed, but knows } \\
\text { how to perform }(\mathrm{N}=21)\end{array}$} & \multicolumn{2}{|c|}{$\begin{array}{c}\text { Do not know how to } \\
\text { perform }(N=21)\end{array}$} \\
\hline & & $\mathrm{n}$ & $\%$ & $\mathrm{n}$ & $\%$ & $\mathrm{n}$ & $\%$ \\
\hline & Anemia treatment & 25 & 100.0 & 0 & 0.0 & 0 & 0.0 \\
\hline & Asthma treatment & 25 & 100.0 & 0 & 0.0 & 0 & 0.0 \\
\hline & Epigastric pain/ peptic ulcer treatment & 25 & 100.0 & 0 & 0.0 & 0 & 0.0 \\
\hline & Back pain treatment (lombar pain) & 25 & 100.0 & 0 & 0.0 & 0 & 0.0 \\
\hline & Superficial mycoses treatment & 25 & 100.0 & 0 & 0.0 & 0 & 0.0 \\
\hline & Request blood examination on fecal occult & 24 & 96.0 & 1 & 4.0 & 0 & 0.0 \\
\hline & Recurrent urinary tract infection treatment & 24 & 96.0 & 1 & 4.0 & 0 & 0.0 \\
\hline & Recurrent sinusitis treatment & 24 & 96.0 & 1 & 4.0 & 0 & 0.0 \\
\hline & Skin diseases treatment & 24 & 96.0 & 0 & 0.0 & 1 & 4.0 \\
\hline & 0 Red eye complaints & 23 & 92.0 & 3 & 12.0 & 0 & 0.0 \\
\hline & 1 Allergic rinopatias treatment & 23 & 92.0 & 1 & 4.0 & 1 & 4.0 \\
\hline & 2 Recurrent otitis treatment & 22 & 88.0 & 3 & 12.0 & 0 & 0.0 \\
\hline & 3 Low risk prenatal care & 22 & 88.0 & 1 & 4.0 & 2 & 8.0 \\
\hline & 4 Superficial wounds treatment & 18 & 72.0 & 4 & 16.0 & 3 & 12.0 \\
\hline & 5 Removal of cerúmen & 17 & 68.0 & 8 & 32.0 & 0 & 0.0 \\
\hline & 6 Pap Smear Test & 13 & 52.0 & 11 & 44.0 & 1 & 4.0 \\
\hline & 7 Oxygen therapy & 13 & 52.0 & 9 & 36.0 & 3 & 12.0 \\
\hline & 8 Removal of strange body from the ear & 11 & 44.0 & 9 & 36.0 & 5 & 20.0 \\
\hline & 9 Intramuscular injection & 12 & 48.0 & 11 & 44.0 & 2 & 8.0 \\
\hline & 0 Reduced visual acuity complaints & 12 & 48.0 & 5 & 20.0 & 8 & 32.0 \\
\hline & 1 Subcutaneous injection & 11 & 44.0 & 13 & 52.0 & 1 & 4.0 \\
\hline & 2 High risk prenatal & 11 & 44.0 & 9 & 36.0 & 5 & 20.0 \\
\hline & 3 Removal of strange body of the upper limbs, lower limbs and extremities & s 9 & 36.0 & 10 & 40.0 & 6 & 24.0 \\
\hline & 4 Ureteral catheter insertion & 10 & 40.0 & 11 & 44.0 & 4 & 16.0 \\
\hline & 5 Removal of strange body in the upper airways & 10 & 40.0 & 10 & 40.0 & 5 & 20.0 \\
\hline & 6 Screening on visual acuity & 10 & 40.0 & 7 & 28.0 & 8 & 32.0 \\
\hline & 7 Incision and drainage of abscesses & 9 & 36.0 & 13 & 52.0 & 3 & 12.0 \\
\hline & 8 Epistaxis cauterization (nose bleeding) & 9 & 36.0 & 10 & 40.0 & 6 & 24.0 \\
\hline & 9 Immobilization of exterme wounds & 9 & 36.0 & 9 & 36.0 & 7 & 28.0 \\
\hline & 0 Local anesthetic infiltration & 8 & 32.0 & 15 & 60.0 & 2 & 8.0 \\
\hline & 1 Paronychia drainage (nail infection) & 8 & 32.0 & 9 & 36.0 & 8 & 32.0 \\
\hline & 2 Cryotherapy or chemical therapy for genital warts & 7 & 28.0 & 10 & 40.0 & 8 & 32.0 \\
\hline & 3 Subungual bruise treatment & 7 & 28.0 & 9 & 36.0 & 9 & 36.0 \\
\hline & 4 Removal of contagious mollusk & 6 & 24.0 & 11 & 44.0 & 8 & 32.0 \\
\hline & 5 Sutures & 5 & 20.0 & 18 & 72.0 & 2 & 8.0 \\
\hline & 6 Venous puncture & 5 & 20.0 & 17 & 68.0 & 3 & 12.0 \\
\hline & 7 Electrocardiogram & 4 & 16.0 & 17 & 68.0 & 4 & 16.0 \\
\hline & 8 Insertion of a nasogastric tube/gastric lavage & 4 & 16.0 & 16 & 64.0 & 5 & 20.0 \\
\hline & 9 Removal of ingrown nail & 4 & 16.0 & 14 & 56.0 & 7 & 28.0 \\
\hline & 0 Removal of skin lesions & 4 & 16.0 & 13 & 52.0 & 8 & 32.0 \\
\hline & 1 Removal of strange body on the cornea or conjunctiva & 4 & 16.0 & 8 & 32.0 & 13 & 52.0 \\
\hline & 2 Immobilizing fractures & 3 & 12.0 & 15 & 60.0 & 7 & 28.0 \\
\hline & 3 Removal of callus & 3 & 12.0 & 11 & 44.0 & 11 & 44.0 \\
\hline & 4 Low risk normal delivery & 2 & 8.0 & 19 & 76.0 & 4 & 16.0 \\
\hline & 5 Scraping for fungus determination & 2 & 8.0 & 11 & 44.0 & 12 & 48.0 \\
\hline & 6 Removal of cysts, lipomas and nevi & 1 & 4.0 & 18 & 72.0 & 6 & 24.0 \\
\hline & 7 Cryotherapy (cold treatment) of skin lesions & 1 & 4.0 & 10 & 40.0 & 14 & 56.0 \\
\hline & 8 High risk normal delivery & 1 & 4.0 & 10 & 40.0 & 14 & 56.0 \\
\hline & 9 Acupunture & 1 & 4.0 & 4 & 16.0 & 20 & 80.0 \\
\hline
\end{tabular}

Source: Elaborated by the authors from data collected in the field, 2015-2016. 
Table 3

Unit type, age, sex and percentage of procedures that nurses perform and know how to perform in health region.

\begin{tabular}{|c|c|c|c|c|c|c|}
\hline Health Region & UBS (location type) & Age & Sex & $\begin{array}{c}(\%) \text { of procedures } \\
\text { performed }\end{array}$ & $\begin{array}{l}(\%) \text { of procedures that } \\
\text { are not performed, but } \\
\text { knows how to perform }\end{array}$ & $\begin{array}{l}\text { (\%) of procedures } \\
\text { that do not know } \\
\text { how to perform }\end{array}$ \\
\hline North and South & Urban & 52 & $\mathrm{~F}$ & 38.2 & * & * \\
\hline \multirow[t]{4}{*}{ Barretos (SP) } & Rural & 40 & $\mathrm{~F}$ & 44.1 & * & * \\
\hline & Urban & 51 & $\mathrm{~F}$ & 29.4 & * & * \\
\hline & Urban & 28 & $\mathrm{~F}$ & 32.4 & * & * \\
\hline & $(\%)$ in the region & & & 36.0 & & \\
\hline \multirow[t]{6}{*}{ PEBA (BA/PE) } & Urban & 39 & $\mathrm{~F}$ & 67.6 & 23.5 & 8.8 \\
\hline & Urban & 28 & $\mathrm{~F}$ & 55.9 & 20.6 & 23.5 \\
\hline & Urban & 28 & $\mathrm{~F}$ & 44.1 & 32.4 & 23.5 \\
\hline & Rural & 27 & $\mathrm{~F}$ & 41.2 & 41.2 & 17.6 \\
\hline & Urban & 29 & $\mathrm{~F}$ & 70.6 & 20.6 & 8.8 \\
\hline & $(\%)$ in the region & & & 55.9 & 27.6 & 16.5 \\
\hline Entorno de & Vulnerable Areas & 35 & M & 55.9 & 29.4 & 14.7 \\
\hline \multirow[t]{6}{*}{ Manaus (AM) } & Urban & 33 & $\mathrm{~F}$ & 50.0 & 29.4 & 20.6 \\
\hline & Rural & 44 & $\mathrm{~F}$ & 67.6 & 32.4 & 0.0 \\
\hline & Urban & 33 & $\mathrm{~F}$ & 52.9 & 41.2 & 5.9 \\
\hline & Vulnerable Areas & 36 & $\mathrm{~F}$ & 58.8 & 5.9 & 35.3 \\
\hline & Vulnerable Areas & 43 & $\mathrm{~F}$ & 52.9 & 44.1 & 2.9 \\
\hline & $(\%)$ in the region & & & 56.4 & 30.4 & 13.2 \\
\hline Baixada Cuiabana & Rural & 36 & $\mathrm{~F}$ & 44.1 & 17.6 & 38.2 \\
\hline \multirow[t]{5}{*}{ (MT) } & Urban & 32 & $\mathrm{~F}$ & 55.9 & 23.5 & 20.6 \\
\hline & Urban & 32 & $M$ & 67.6 & 20.6 & 11.8 \\
\hline & Vulnerable Areas & 27 & $\mathrm{~F}$ & 47.1 & 44.1 & 8.8 \\
\hline & Urban & 27 & $\mathrm{~F}$ & 52.9 & 23.5 & 23.5 \\
\hline & $(\%)$ in the region & & & 53.5 & 25.9 & 20.6 \\
\hline Carbonífera/ & Urban & 40 & $M$ & 44.1 & 47.1 & 8.8 \\
\hline \multirow[t]{6}{*}{ Costa Doce (RS) } & Vulnerable Areas & 37 & $\mathrm{~F}$ & 29.4 & 26.5 & 44.1 \\
\hline & Urban & 26 & $\mathrm{~F}$ & 41.2 & 32.4 & 26.5 \\
\hline & Urban & 44 & $\mathrm{~F}$ & 41.2 & 50.0 & 8.8 \\
\hline & Urban & 40 & $\mathrm{~F}$ & $* *$ & ** & ** \\
\hline & Urban & 39 & $\mathrm{~F}$ & 55.9 & 41.2 & 2.9 \\
\hline & $(\%)$ in the region & & & 42.4 & 39.4 & 18.2 \\
\hline
\end{tabular}

* Pre-test questionnaire, did not have the question. **Interviewed did not answer the question. 
Distribution of procedures, health services and actions of nurses at the UBS that perform, do not perform, but knows how to perform and do not know how to perform.

\begin{tabular}{|c|c|c|c|c|c|c|}
\hline \multirow[t]{2}{*}{ Health procedures, services and actions } & \multicolumn{2}{|c|}{ Performed $(\mathrm{N}=25)$} & \multicolumn{2}{|c|}{$\begin{array}{l}\text { Are not performed, but knows } \\
\text { how to perform }(\mathrm{N}=21)\end{array}$} & \multicolumn{2}{|c|}{$\begin{array}{l}\text { Do not know how to } \\
\text { perform }(\mathrm{N}=\mathbf{2 1})\end{array}$} \\
\hline & $\mathrm{n}$ & $\%$ & $\mathrm{n}$ & $\%$ & $\mathrm{n}$ & $\%$ \\
\hline 1 Perform a Pap smear exam & 25 & 100.0 & 0 & 0.0 & 0 & 0.0 \\
\hline 2 Referral patients to other services & 24 & 96.0 & 0 & 0.0 & 1 & 4.8 \\
\hline 3 Interpret a Pap smear result & 24 & 96.0 & 0 & 0.0 & 1 & 4.8 \\
\hline 4 Perform low risk prenatal care & 24 & 96.0 & 1 & 4.8 & 0 & 0.0 \\
\hline 5 Perform acute cases & 23 & 92.0 & 1 & 4.8 & 1 & 4.8 \\
\hline 6 Perform puericulture consultation & 23 & 92.0 & 1 & 4.8 & 1 & 4.8 \\
\hline 7 Interpret laboratorial exams (clinical analysis) & 22 & 88.0 & 0 & 0.0 & 3 & 14.3 \\
\hline 8 Perfrom wound bandaging & 22 & 88.0 & 2 & 9.5 & 1 & 4.8 \\
\hline 9 Request laboratorial tests (clinical analysis) & 21 & 84.0 & 3 & 14.3 & 1 & 4.8 \\
\hline 10 Removal of sutures & 20 & 80.0 & 4 & 19.0 & 1 & 4.8 \\
\hline 11 Apply vaccines & 20 & 80.0 & 3 & 14.3 & 2 & 9.5 \\
\hline 12 Communicate diagnosis to patients (such as diabetes, hypertension) & 18 & 72.0 & 5 & 23.8 & 2 & 9.5 \\
\hline 13 Prescribe bandaging & 18 & 72.0 & 5 & 23.8 & 2 & 9.5 \\
\hline 14 Prescribe medications that are basic in drug store & 15 & 60.0 & 5 & 23.8 & 5 & 23.8 \\
\hline 15 Prescribing treatment for vulvovaginitis & 15 & 60.0 & 6 & 28.6 & 4 & 19.0 \\
\hline 16 Insert vesical probe for relief & 15 & 60.0 & 9 & 42.9 & 0 & 0.0 \\
\hline 17 Interpret imaging examinations & 14 & 56.0 & 1 & 4.8 & 10 & 47.6 \\
\hline 18 Insert vesical probe & 13 & 52.0 & 10 & 47.6 & 1 & 4.8 \\
\hline 19 Request imaging examinations & 11 & 44.0 & 5 & 23.8 & 9 & 42.9 \\
\hline 20 Renew prescription & 8 & 32.0 & 12 & 57.1 & 4 & 19.0 \\
\hline 21 Perform immobilizations & 8 & 32.0 & 8 & 38.1 & 6 & 28.6 \\
\hline 22 Insert a nasogastric tube & 8 & 32.0 & 15 & 71.4 & 0 & 0.0 \\
\hline 23 Perform high risk prenatal & 7 & 28.0 & 8 & 38.1 & 10 & 47.6 \\
\hline 24 Insert nasoenteral tubes & 6 & 24.0 & 13 & 61.9 & 3 & 14.3 \\
\hline 25 Perform an electrocardiogram & 5 & 20.0 & 12 & 57.1 & 6 & 28.6 \\
\hline $\begin{array}{l}26 \text { Prescribe medications for patients suffering from chronic diseases } \\
\text { already diagnosed }\end{array}$ & 4 & 16.0 & 13 & 61.9 & 8 & 38.1 \\
\hline 27 Interpret tuberculin skin test results (PPD) & 4 & 16.0 & 11 & 52.4 & 9 & 42.9 \\
\hline 28 Perform abscess drainage & 2 & 8.0 & 13 & 61.9 & 10 & 47.6 \\
\hline 29 Perform emergency normal delivery & 2 & 8.0 & 10 & 47.6 & 12 & 57.1 \\
\hline 30 Prescribe controlled medications & 1 & 4.0 & 7 & 33.3 & 17 & 81.0 \\
\hline 31 Perform suturing & 1 & 4.0 & 7 & 33.3 & 17 & 81.0 \\
\hline 32 Local Anesthesia & 1 & 4.0 & 4 & 19.0 & 20 & 95.2 \\
\hline 33 Perform normal delivery & 0 & 0.0 & 16 & 76.2 & 9 & 42.9 \\
\hline 34 Perform tuberculin skin test (PPD) & 0 & 0.0 & 9 & 42.9 & 15 & 71.4 \\
\hline
\end{tabular}

Source: Elaborated by the authors from data collected in the field, 2015-2016. 
female $(n=23)$, with ages ranging from 26 to 52 years old (Table 3 ). Most of the nurses were statutory $(n=21)$, followed by temporary worker $(n=4)$ and a fellowship. The total number of the interviewees, 21 mentioned to have a specialist title, 10 were in family health and/or public health. Only four reported working in other location(s), besides the unit in which they were interviewed.

The interviewed nurses in the regions of Entorno Manaus, PEBA and Baixada Cuiabana reported, in general, to perform a higher number of procedures when compared to other visited regions, respectively $56.4 \%, 55.9 \%$ and $53.5 \%$ (Table 3 ). Analyzing the interviewed individually, the one who mentioned to perform a great number of procedures also worked in PEBA Network (70.6\%), in a city far away, in the same location where the physician who performs a higher number of activities (Table 1 and 3 ). Those who were interviewed in the regions of Barretos and Carbonífera/Costa Doce, in contrast, have reported to perform a smaller number of procedures, in general, have reported performing a small number of procedures. In these regions are also the professionals that, individually, execute a small quantity of procedures, working in nearby cities to the respective health regions.

When analyzing only the nurses working in the rural areas, the professionals who perform a great number of procedures are found in Barretos (44.1\%) and Entorno Manaus (67.6\%) regions, and those who perform a small amount of procedures are found in the rural areas of PEBA $(41.2 \%)$ and Baixada Cuiabana (44.1\%) (Table 3). No relation was found in the scope of personal characteristics, such as the interviewees' sex and age.

Among the activities listed for the nurses, the most common performance in the UBS were: the accomplishment and interpretation of the Pap smear results, referral of the patients to other services, the achievement of low risk prenatal care, care for acute cases, childcare consultation, solicitation and interpretation of laboratorial tests, achievement of bandaging, suture removal and vaccines application (Table 4).

The nurses, however, reported to know how to perform more procedures than those performed in the units. Among the regions visited, Carbonifera / Costa Doce showed the highest gap between pratice and knowledge is the most.

Among the procedures that the nurses know how to perform, but did not perform in practice, more than half reported to renew prescriptions, insert a nasogastric tube, nasoenteric, perform drainage of abscess, perform normal delivery and prescribe medications for patients with chronic diseases already diagnosed. For this activity, an interviewee adds:

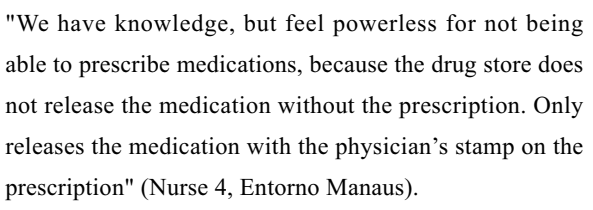

Among the reasons given for not carrying out the activities that they know how to perform at the basic health units is the lack of equipment and infrastructure:

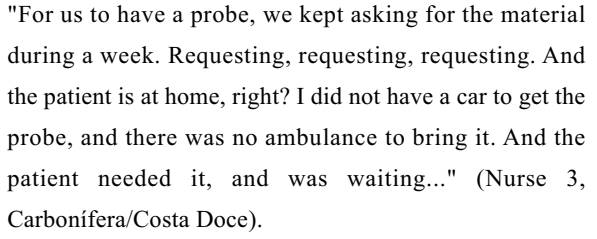

"For us to have a probe, we kept asking for the material during a week. Requesting, requesting, requesting. And the patient is at home, right? I did not have a car to get the probe, and there was no ambulance to bring it. And the patient needed it, and was waiting..." (Nurse 3, Carbonífera/Costa Doce).

Most of the interviewees agreed with the extension of the scope of practice of the category and they highlighted, in particular, the importance of extending the list of medications that nurses could prescribe at the primary healthcare:

"It would be very useful, because we catch much candidiasis here, lots of Gardnerella. You know what it is used for, you know what you have to do and cannot treat it. You have to be referral. If there is not to the gynecologist, we generally have for the patient what they [clinicians] only prescribe, they do not have to re-examine" (Nurse 5, Carbonífera / Costa Doce).

"When I need it I go there in his office [the physician], I discuss the case and he prescribes me the medication. But is that, right?! Every time I see a patient with, for example, candidiasis. Then I have to go there, knock on the physician's door and wait... sometimes the door is closed, then I wait for 20 minutes... And the patient is here... Then you cannot call someone else! [...]" (Nurse 3, Carbonífera/Costa Doce).

This same interviewee said that, in specific cases, already writes out the prescription, but it is the physician who has to stamp the prescription:

"He relies on me a lot. Sometimes I make out the prescription and he just stamps it. But it is complicated this way, right?!" (Nurse 3, Carbonífera / Costa Doce).

Several professionals still mention about the 
difficulties encountered in the practice when there is no physician in the unit or when this professional is overloaded, and they reported what they have already done, in this case:

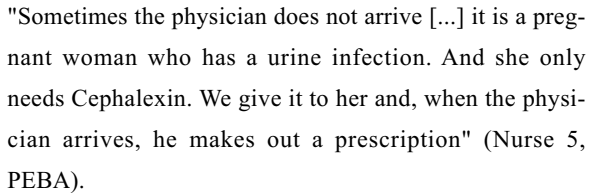

"There is a time when there is no physician at all. You have to figure out what to do. I have a colleague who works in the countryside and she is all alone, and then, that's it, 'zefini'! There is no physician. She has to solve everything!" (Nurse 6, Entorno Manaus).

"Some medications we do not need any prescription but, for example, a patient with a headache or a child with a fever, when the physician is very busy, you end up giving a Paracetamol, a Dipyrone. So, the simplest cases, when the physician is busy, we, ourselves solve the problem Now, if the patient continues with the same symptom, we ask him to come back" (Nurse 4, PEBA).

In a health unit in Baixada Cuiabana, a nurse found a solution, when she was without a physician on the team, she performed a referral or requested an assistance from another professional of another team:

\footnotetext{
"When I see that it is necessary I send to a polyclinic or a UPA [Health Care Unit]. Or I ask an examination and, if the result is altered, I ask the physician here [the other team]. The physician here on the other side is always giving me support" (Nurse 2, Baixada Cuiabana).
}

For a nurse from Baixada Cuiabana, the knowledge and the broadening of the scope in rural areas is even more important:

"For those who work in the rural area is important, because usually the physician is not around all the time. [...] We who live there. Then, especially at night, if you feel something, the people will call the nurse" (Nurse 2, Baixada Cuiabana).

It is noteworthy that the nurse who was interviewed in the rural area of this region, when comparing to others, was the one who performed the smallest number of procedures.

Despite agreeing with the extension of the scope of nurses, the interviewees reported that this should occur in a safe manner:
"Adequate training, backed by appropriate legal actions, backed by the Council $[. .$.$] what was the best for the$ patient. In fact it has to be good for him." (Nurse 1, Entorno Manaus).

\section{Discussion}

This exploratory study sought to identify the scopes of medical and nursing professionals, besides of raising the main difficulties and barriers to achieve certain activities and procedures.

The results of this study indicate that physicians and nurses in the two health regions of PEBA network and Entorno Manaus performed a greater number of procedures. A study developed with active professionals in the Programa Mais Médicos (PMM) (More Physicians Program) demonstrated that working in the geographic North region is a factor that contributes to the accomplishment of a great quantity of procedures. 2 In contrast, the Northeast region is the one that performs a lesser quantity of procedures, according to the data in this study.

It is interesting to note that all of the interviewed physicians in the rural units were performing a greater number of procedures in relation to their peers in the region. This relation between a expanded scope of practice of physicians and their work in rural and remote areas have been identified in several studies.2,20,21 Despite that it was not so evident in the nursing professionals, it is suggestive that a nurse who works in a rural unit of a riveside community, with only fluvial access, in Entorno de Manaus, performs more procedures than others interviewed in the same region.

When we saw the results individually, the highest percentages of procedures performed, both for physicians and for nurses, were found in PEBA Network, in a city between the most distant health region, more than two hours by car, and presented a shortage of physicians according to the Índice de Escassez de Médicos (Shortage of Physicians Indice) at the APS.22 In relation to far away cities, the study by Girardi et al. ${ }^{2}$ showed that professionals in these locations perform a great number of procedures.

The results also demonstrate that the scope of practice on health professionals is related to multiple factors and faces several barriers. The interviewees in both categories reported to know how to perform various procedures and health actions that are not performed in the practice. The reasons found in the literature for a reduced scope of practice of health professionals include, among others, personal 
factors, which relate to individual preferences, factors related to work, as of contractual restrictions, lack of support and infrastructure, and overloaded work; competence factors, such as the lack of training and qualification, and external or community factors, such as the lack of demand from the population. 2,23-27 In this present study, the main reasons given were similar, the professionals mentioned, among others, the lack of access to do exams and inadequate infrastructure, restrictions of protocols and city guidelines, legal restriction and the lack of training.

The professionals' practices are also related to the understanding of what the population has on the APS, as the fact that the population does not consider, in some moments, that the UBS is preferential in SUS and/or even requires referrals to other specialties, situations mentioned by some interviewees. A study on the therapeutic itinerary that patients perform in search of treatment in the public system indicates that one of the issues is related to the mechanisms and understanding that the population sees in the health and disease treatment, such as the possibility of great success in solving their treatments. 28 In other words, many times patients seek other medical institutions and medical specialties of secondary and tertiary units, thinking that their demands in dealing with health will be quickly resolved.

The relation between the scope of practice of physicians and nurses was evident in the interviews, especially in the nurses' discourse. The issues in whether sharing tasks and the actual transference of tasks - Task shifting from physicians to nurses have been quite debated in international studies. Several countries have already expanded the nurses' functions, as it is the case of nurses with advanced training - Nurse Practitioners, who are trained to act especially in places where there is evidence of shortage of physicians, in which they undertake activities such as prescribing medications, ordering additional tests, and diagnosing health problems. ${ }^{13,29}$ A review study on cost-effectiveness of nurse practitioners have concluded that the use of the same nurses working in primary care contribute to reduce costs and increase access, since they can perform basic tasks and routine care traditionally performed by physicians. 29

The nurses from the present study demonstrate to agree on the extension of their scope, since they have competence for such, in other words, receive appropriate training and have legal support. The fact of the present study indicates that some nurses in practice already perform activities such as diagnosis and prescribing medications, in which the physician only signs the prescription, reinforces the urgent need to reduce barriers between these two professions.

The physicians also demonstrated in agreeing with the expansion of their own practices at the APS, and attribute as advantages, among others, the reduction of waiting lines, greater effectiveness and better tracking of the patient. However, on the transference of tasks and responsibilities to the nurses, although one of the interviewed physicians had reported the need to formalize the sharing of tasks, this does not reflect on the category of the physicians' opinion. In fact, the increased competition within the interprofessional has led to a dispute to expand the monopoly in the exercise of activities and professional services in the health area. The Lei do Ato Médico (Law of the Physician Act) is a clear example of this situation. 30

\section{Final Considerations}

An important limitation to be considered in this study, by logistical and budgetary issues, was the impossibility of performing more interviews in far away, remote and unassisted cities in the studied regions, mainly because these are locations that allow to identify a great variation and extension of the scope of practice among medical and nursing professionals, as shown in previous studies on the issue. $2-9,20-23$

In any case, if it is not obvious, the results presented in this exploratory study reinforce the importance to reform the regulations of health professions in Brazil. This reform would implicate on the extrapolation of activities legally defined and should take into account the context of practice, including city norms and protocols, the levels of competence and experience of the professionals, as well as the patients' necessities and demands.

The construction of this reform must transcend the corporate conflicts and allow the structuring of a regulatory system to be more flexible, able to ensure the integration between the professions, especially in those regions that are most unassisted, as well as to be able to promote continuous improvement in the health service provisions and expand the access and the resolution at the APS. 


\section{References}

1. Federation of State Medical Boards of the United States. Assessing Scope of Practice in Health Care Delivery: Critical Questions in Assuring Public Access and Safety; 2005 .

2. Girardi SN, Carvalho CL, Pierantoni CR, Costa JO, Stralen ACS, Lauar TV, David RB. Avaliação do escopo de prática de médicos participantes do Programa Mais Médicos e fatores associados. Ciênc Saúde Coletiva. 2016; 21 (9): 2739-48.

3. Rosenthal EL, Rush CH, Allen CG. Understanding Scope and Competencies: A Contemporary Look at the United States Community Health Worker Field [relatório de pesquisa]. Bulding National Consensus on CHW Core Roles, Skills, and Qualities; 2016. [acesso em 24 mai 2017]. Disponível em: https://sph.uth.edu/dotAsset/ 28044e61-fb10-41a2-bf3b-07efa4fe56ae.pdf

4. Baranek PM. A review of scopes of practice of health professions in Canada: A balancing act. Toronto: Health Council of Canada; 2005.

5. Wong E, Stewart M. Predicting the scope of practice of family physicians. Can Fam Physician. 2010; 56 (6): 21925 .

6. Tepper JD, Schultz SE, Rothwell DM, Chan BTB. Physician services in rural and Northern Ontario. ICES investigative report. Toronto: Institute for Clinical Evaluative Sciences; 2006.

7. Poghosyan L, Nannini A, Smaldone A, Clarke S, O'Rouke $\mathrm{NC}$, Rosato BG, et al. Revisiting scope of practice facilitators and barriers for primary care nurse practitioners: a qualitative investigation. Policy Polit Nurs Pract. 2013; 14 (1): 6-15.

8. Sibbald B. Skill mix and professional roles in primary care In: What is the future for a primary care-led NHS? National Primary Care Researchand Development Series. Oxford: Radcliffe Medical Press; 1996.

9. Freund T, Everett C, Griffiths P, Hudon C, Naccarella L, Laurant M. Skill mix, roles and remuneration in the primary care workforce: who are the healthcare professionals in the primary care teams across the world? Int J Nurs Stud. 2015; 52 (3): 727-43.

10. Hooker RS. Hogan K, Leeker E. The Globalization of the Physician Assistant Profession. J Physician Assist Educ. 2007; 18 (3): 76-85.

11. Verhuslt L, Forrest CB. To Count Heads or to Count Services? Comparing Population-to-Physician Methods with Utilization-Based Methods for Physician Workforce Planning: A Case Study in a Remote Rural Administrative Region of British Columbia. Health Care Policy. 2007; 2(4):178-192.

12. World Health Organization (WHO). Task shifting to tackle health worker shortages [Internet]. 2007 [acesso em 24 ma 2017]. Disponível em: http://www.who.int/healthsystems/ task shifting booklet.pdf.

13. Toso BRGO, Filippon J, Giovanella L. Nurses' performance on primary care in the National Health Service in England. Rev Bras Enferm. 2016; 69 (1): 169-77.
14. Instituto de Medicina Social (IMS/UERJ) \& Estação de Pesquisa de Sinais de Mercado em Saúde (EPSM/ NESCON/FM/UFMG). Regulação do Trabalho e das Profissões em Saúde [relatório de pesquisa]. [acesso em 24 mai 2017]. Disponível em:http://epsm.nescon.medicina. ufmg.br/epsm/Relate_Pesquisa/Relatorio_final_pesquisa_r egulacao_completo.pdf.

15. Viana ALA, Ferreira MP, Cutrim MAB, Fusaro ER, Souza MR, Mourão L, Chancharulo AP, Mota PHS. Política de regionalização do SUS em debate: avanços e impasses da implementação das regiões e redes no Brasil. Novos Caminhos, n.15. Pesquisa Política, Planejamento e Gestão das Regiões e Redes de Atenção à Saúde no Brasil. [acesso em 24 mai 2017]. Disponível em www.regiaoeredes.com.br

16. Jaakkimainen RL, Sood PR, Schultz SE. Office-based procedures among urban and rural family physicians in Ontario. Can Fam Physician. 2012; 58 (10): 578-e87.

17. O'Neill T, Peabody MR, Blackburn BE, Peterson LE. Creating the Individual Scope of Practice (I-SOP) scale. J Appl Meas. 2014; 15 (3): 227-39.

18. Brasil. Ministério da Saúde (MS). Secretaria de Atenção à Saúde. Departamento de Atenção Básica. Procedimentos. Série A. Normas e Manuais Técnicos Cadernos de Atenção Primária, n. 30, Brasília, DF; 2011.

19. Bardin L. Análise de conteúdo. São Paulo: Edições 70; 2011.

20. Baker E, Schmitz D, Epperly T, Nukui A, Miller CM. Rural Idaho family physicians' scope of practice. J Rural Health. 2010; 26 (1): 85-9.

21. Hutten-Czapski P, Pitblado R, Slade S. Short report: Scope of family practice in rural and urban settings. Can Fam Physician. 2004; 50: 1548-50.

22. Estação de Pesquisa de Sinais de Mercado (EPSM). Identificação de Áreas de Escassez de Recursos Humanos em Saúde no Brasil [relatório de pesquisa]. Belo Horizonte: EPSM/NESCON/ FM/UFMG; 2012. [acesso em 24 mai 2017]. Disponível em: http://epsm.nescon.medicina.ufmg. br/epsm/Relate_Pesquisa/Identifica $\% \mathrm{C} 3 \% \mathrm{~A} 7 \% \mathrm{C} 3 \% \mathrm{~A} 3 \mathrm{o} \%$ $20 \mathrm{de} \% 20 \% \mathrm{C} 3 \% \mathrm{~A} 1$ reas $\% 20 \mathrm{de} \% 20$ escassez $\% 20 \mathrm{de} \% 20$ RHS\%20no\%20Brasil.pdf

23. National Rural Health Alliance Inc. Advanced nursing practice in rural and remotes areas. Position paper. 2005. [acesso 24 mai 2017]. Disponível em: http://ruralhealth.org. $\mathrm{au} /$ sites/default/files/position-papers/position-paper-05-0701.pdf

24. Coutinho AJ, Cochrane A, Stelter K, Phillips Jr RL, Peterson LE. Comparison of Intended Scope of Practice for Family Medicine Residents With Reported Scope of Practice Among Practicing Family Physicians. JAMA. 2015; 314 (22): 2364-72.

25. Chen FM, Huntington J, Kim S, Phillips WR, Stevens NG. Prepared But Not Practicing: Declining Pregnancy Care Among Recent Family Medicine Residency Graduate. Fam Med. 2006; 38 (6): 423-6. 
26. Tong ST, Makaroff LA, Xierali IM, Parhat P, Puffer JC, Newton WP, Bazemore AW. Proportion of family physicians providing maternity care continues to decline. J Am Board Fam Med. 2012; 25 (3): 270-1.

27. Chan BTB, Schultz SE. Supply and utilization of general practitioner and family physician services in Ontario: Institute for Clinical Evaluative Sciences; 2005.

28. Pereira DN. Incertezas de pacientes no sistema público de saúde. Physis: Rev Saúde Coletiva. 2010; 20 (1): 145-69.

Received on June 1st, 2017

Final version presented on September 30th, 2017

Approved on October 5th, 2017
29. Wong ST, Farrally V. The utilization of nurse practitioners and physician assistants: a research synthesis. Prepared for the Michael Smith Foundation for Health Research. 2013. [acesso em 24 mai 2017]. Disponível em: http://www.msfhr.org/sites/default/files/Utilization_of_Nur se_Practitioners_and_Physician_Assistants.pdf

30. Girardi SN. Dilemas da regulamentação profissional na área da Saúde: questões para um governo democrático e inclusionista. Rev Latinoam Estudos Del Trabajo. Carabobo. 2002; 8 (15): 67-85. 